\title{
Interaction between Kilauea and Mauna Loa
}

\section{Last year witnessed an unexpected communication between this pair of volcanoes.}

A fter almost a decade of very slow rates of deformation, Mauna Loa in Hawaii, the largest volcano on Earth, began inflating in May 2002; at the same time, a high-volume effusive episode began at its neighbour Kilauea. We have found a correlation between these events at a very short timescale, detected by continuous deformation monitoring. This remarkable observation suggests that there is a crustal-level interaction between the magma systems of Mauna Loa and Kilauea, reviving a centuryold controversy over the relationship between these two volcanoes on the basis of differences in their lava chemistry and in their patterns of eruptive behaviour ${ }^{1-5}$.

To evaluate the significance of the temporal correlation, we used a Monte Carlo simulation to predict the probability of a rate change at Mauna Loa occurring within one week of an effusive episode at Kilauea during any given 1,000-day interval (about the length of the global positioning system (GPS) time series). Because we used upper-bound estimates of the frequency of such events three effusive events per year on Kilauea and one deformation-rate change at Mauna Loa every four years - the simulation should yield an upper boundary on the probability of random coincidence, which we find to be less than one in ten. Compared with this figure, the plausibility of a causal interaction between the two volcanoes seems high.

Beyond pure coincidence, how can this correlation be explained? One possibility is a relaxation of stress on Mauna Loa's flank

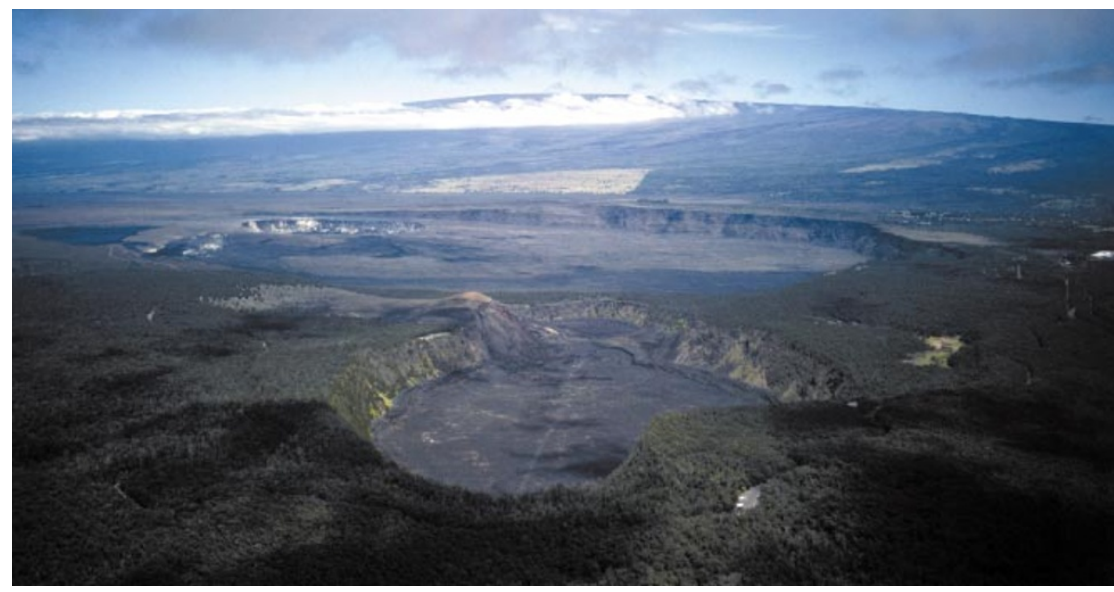

Figure 2 Summit conference: westward view across the crater of the Hawaiian volcano Kilauea, with Mauna Loa in the background

that allowed magma to rise to shallow levels. However, because of the small magnitude of the deflation at Kilauea's summit that accompanied the effusive event, it is unlikely that elastic stress transfer could have affected Mauna Loa's magma system significantly.

Another possibility is that there was an increase in magma supply to both volcanoes, contrary both to geochemical models that require mantle-level differences in the parent magmas $^{4}$, and to the suggestion, based on long-term eruptive behaviour, that they compete for magma supply ${ }^{5}$. Also contradictory to this explanation is the lack of rapid inflation immediately before the effusive event. However, in the months leading up to the event, Kilauea's shallow magma system
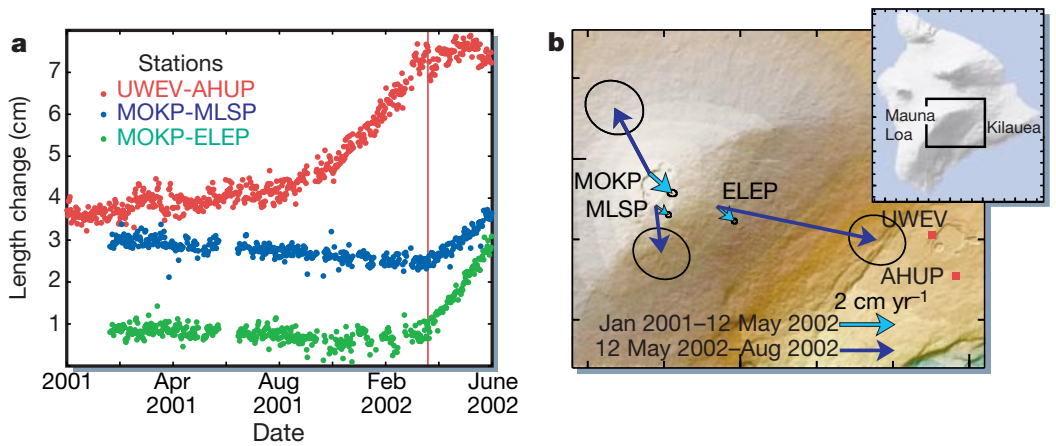

Figure 1 Recent global positioning system (GPS) results from the Mauna Loa and Kilauea volcanoes in Hawaii. a, Changes in line length between GPS stations. Time series for stations spanning the summit caldera of Mauna Loa (blue) show the reversal from an almost

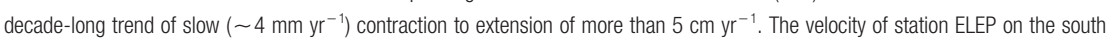
flank also accelerated to more than ten times its previous rate (green). The rate changes coincide with the onset of an effusive event at Kilauea on 12 May 2002 (vertical red line) that emanated from a new vent at the base of Pu'u 'O'o cone on the east rift zone. This event followed a period of inflation at Kilauea (as shown by the extension on the UWEV-AHUP baseline, red) that began in late 2001 and continued, more slowly after 12 May, until late July. b, Horizontal-velocity vectors on Mauna Loa (with the motion of the Pacific Plate removed) before and after the 12 May event. The current pattern of deformation at Mauna Loa's summit is consistent with inflation of the magma reservoir, imaged with geodetic data during the volcano's latest eruption, in 1984 (ref. 6). Error ellipses represent 95\% confidence regions and are based on repeatability about a constant velocity. had been undergoing a slow pressurization (Fig. 1). If this were the first sign of a pulse of magma that was common to both volcanoes, it seems remarkable that it would take a further six months to reach Mauna Loa's shallow system, reaching it by coincidence at the same time as Kilauea produced voluminous flows from a new vent.

Alternatively, the inflation that began in late 2001 at Kilauea may have resulted from reduced lava-transport capacity at the old vent, as it occurred during a period of decreasing surface effusion. Moreover, the extension rate at Kilauea abruptly slowed at the start of the effusive event, turning to contraction in late July, while Mauna Loa continued to extend (Fig. 1).

Although we do not discount the idea of a shared pulse of magma to both volcanoes (Fig. 2), there is a possibility that does not require it. A pulse of magma introduced into Mauna Loa's plumbing system could have increased the pressure in Kilauea's adjacent, and already overpressurized, shallow magma system. The existing instability at Kilauea could have amplified the effect of what is likely to have been a very small perturbation, providing the added stress that was necessary to trigger the effusive episode.

\section{Asta Miklius, Peter Cervelli}

US Geological Survey, Hawaiian Volcano Observatory, Hawaii National Park, Hawaii 96718, USA

e-mail: asta@usgs.gov

1. Dana, J. D. Am. J. Sci. 60, 235-244 (1850).

2. Jagger, T. A. Am. J. Sci. 193, 255-288 (1917).

3. Rhodes, J. M. et al. Nature 337, 257-260 (1989).

4. Frey, F. A. \& Rhodes, J. M. Phil. Trans. R. Soc. Lond. A 342, 121-136 (1993).

. Klein, F. W. J. Geophys. Res. 12, 1-35 (1982).

6. Lockwood, J. P. et al. US Geol. Surv. Prof. Pap. 1350, 537-570 (1987).

Competing financial interests: declared none 